\title{
Article \\ Feasibility of a Helium Closed-Cycle Gas Turbine for UAV Propulsion
}

\author{
Emmanuel O. Osigwe ${ }^{1,2, *(\mathbb{C}}$, Arnold Gad-Briggs ${ }^{1,2}$ and Theoklis Nikolaidis ${ }^{2}(\mathbb{D}$ \\ 1 EGB Engineering, Southwell NG25 0BB, UK; a.a.gadbriggs@cranfield.ac.uk \\ 2 Centre for Propulsion Engineering, School of Aerospace Transport and Manufacturing (SATM), \\ Cranfield University, Cranfield MK43 0AL, UK; t.nikolaidis@cranfield.ac.uk \\ * Correspondence: eosigwe@cranfield.ac.uk
}

Featured Application: UAV Propulsion System.

\begin{abstract}
When selecting a design for an unmanned aerial vehicle, the choice of the propulsion system is vital in terms of mission requirements, sustainability, usability, noise, controllability, reliability and technology readiness level (TRL). This study analyses the various propulsion systems used in unmanned aerial vehicles (UAVs), paying particular focus on the closed-cycle propulsion systems. The study also investigates the feasibility of using helium closed-cycle gas turbines for UAV propulsion, highlighting the merits and demerits of helium closed-cycle gas turbines. Some of the advantages mentioned include high payload, low noise and high altitude mission ability; while the major drawbacks include a heat sink, nuclear hazard radiation and the shield weight. A preliminary assessment of the cycle showed that a pressure ratio of 4 , turbine entry temperature (TET) of $800{ }^{\circ} \mathrm{C}$ and mass flow of $50 \mathrm{~kg} / \mathrm{s}$ could be used to achieve a lightweight helium closed-cycle gas turbine design for UAV mission considering component design constraints.
\end{abstract}

Keywords: UAV; propulsion system; closed-cycle engines; gas turbines; mission requirement

check for

updates

Citation: Osigwe, E.O.; Gad-Briggs, A.; Nikolaidis, T. Feasibility of a Helium Closed-Cycle Gas Turbine for UAV Propulsion. Appl. Sci. 2021, 11, 28. https://dx.doi.org/10.3390/app11 010028

Received: 30 November 2020 Accepted: 18 December 2020 Published: 22 December 2020

Publisher's Note: MDPI stays neutral with regard to jurisdictional claims in published maps and institutional affiliations.

Copyright: () 2020 by the authors. Licensee MDPI, Basel, Switzerland. This article is an open access article distributed under the terms and conditions of the Creative Commons Attribution (CC BY) license (https: / / creativecommons.org/ licenses/by/4.0/).

\section{Introduction}

In the context of this paper, the term unmanned aerial vehicles (UAV), referred to as uncrewed aerial vehicles, are aircraft that use aerodynamic forces to provide lift either directly or by forward motion, with no human on board and controlled autonomously or remotely. Hence, throughout this paper, the term uncrewed aerial vehicle is used interchangeably with remotely piloted vehicles (RPV) and uncrewed air system (UAS). UAV, UAS and RPV have been around since World War II, and there is growing interest in the use of uncrewed aircraft for special mission requirements [1], due to the advent of better technologies to support the intelligence of controlled UAVs. To this end, there are projections for significant growth in the use of UAVs in both civil and military applications due to the added economic and technological value related to them [2,3]. Despite these projections, there are still many challenges facing the industry, with the salient ones being the choice of the propulsion system, the energy source, the conversion system, the fluid media, and the thrust converter. The considerations of energy source, conversion system, fluid media and thrust converter are linked to the choice of the propulsion system.

The choice of the propulsion system is vital in terms of sustainability, usability, noise, controllability, reliability, and technology readiness level (TRL). Unlike the crewed aircraft vehicles, the design for UAVs will also need to meet long-endurance criteria, a duty cycle portrayed by heavyweight and high-altitude flight, compactness, and payload requirements. Hence, a propulsion system that does not meet these demands will not make any economic sense and will be less applicable for either military or civil usage. With sustainability, the goal will be to have a system that would not have a severe impact on the environment, as well as achieving the objective of a net-zero carbon footprint. 
The complexity of selecting and exploiting the propulsive system capability to meet all assumed requirements is not an easy task, but one that requires continuous optimisation. Within this context, several propulsion systems have been considered as part of ongoing innovative research programs. A broad spectrum of these initiatives includes open, closed and semi-closed propulsion systems such as the use of reciprocating engines (diesel engines), Rankine, Stirling, and Brayton cycles (Turbojet, Turboprop, Turbofan), as well as battery and fuel-cell, powered propulsion systems. For example, in the work of Rogers, [4], the author proposed the use of a small turbofan or turbojet for UAV propulsion with the aim that a decrease in both the engine size and frontal area would decrease fuel consumption and improve engine affordability. The work addresses the drawback of remarkably high fuel consumption associated with the use of turbojet or turbofan. An example of a Turbojet UAV is the Bombardier CL-289 [1] developed by Dornier GmbH in Munich as a tri-national project between Canada, France and Germany with output thrust of $236 \mathrm{kN}$ and the Rolls-Royce RA-4a Global Hawk [1] an example of Turbofan UAV.

Similarly, Andrei et al. [5] discussed the modelling challenges for turbojet UAV using a one-dimensional correlation model to access the performance and operational requirements for a UAV mission. There are also several proposals to use fuel-cell and battery-powered propulsion recorded in the works of Osenar et al. [6] and Gonzalez-Espasand et al. [7]. The stated advantages of the fuel cell-based system include higher efficiency and zeroemission compared to fossil fuel technology. However, the high cost of production and increased sensitivity to fuel contamination could create additional complexity. As the drive for a reduction in the cost of lithium is sustained and technology to reduce the mass-toenergy ratio to less than a quarter, battery-powered propulsion system could lead the UAV missions. Additionally, Tacconi et al. [8] compared the use of a semi-closed cycle to open Brayton cycles for medium-altitude UAV mission. The result from their work showed a slight performance improvement with the semi-closed cycle compared against the large open cycles. This is because the semi-closed cycle offered a compact and efficient design for medium-altitude UAV missions [9].

The use of reciprocating internal combustion engines (ICE) has also been documented in the works of Harper and Jansen [10], Adamski [11] and Marcellan, [12], which is the most common form of the propulsion system used for the UAVs, ranging between 1-150 kW. The reciprocating engines are widely used because of weight and high power to weight ratio, but its disadvantage is hinged on its noisy operation, vibrational challenges at high revolution per minute and cooling requirement. The reciprocating piston engine has many pressurised seals that often fails, leading to significant loss of power or engine failure. An example of the UAVs with reciprocating ICE includes the General Atomics MQ-1 Predator developed by General Atomics in Poway, US. The UAV weighing $68 \mathrm{~kg}$ (engine weight) with 115 horsepower output [1]. Others are the Northrop Grumman RQ-5A Hunter developed in Fort Hood, Texas, Insitu ScanEagle A [13] and Honeywell Micro Air Vehicle (MAV). Table 1 provides an overview of the various UAV propulsion without mentioning the close-cycle options. The comparison of the closed cycle propulsion system is highlighted in Section 2 of this paper. 
Table 1. Unmanned aerial vehicle (UAV) propulsion systems overview [12].

\begin{tabular}{|c|c|c|c|c|c|c|}
\hline Pow & Plant & $\begin{array}{l}\text { Altitude } \\
(\mathbf{k m})\end{array}$ & Speed & $\begin{array}{l}\text { SFC @ Cruise } \\
(\mathrm{kg} / \mathrm{kWh})\end{array}$ & $\begin{array}{c}\text { Power (or } \\
\text { Thrust) (kW) }\end{array}$ & $\begin{array}{c}\mathrm{P} / \mathrm{W} \\
(\mathrm{kW} / \mathrm{kg})\end{array}$ \\
\hline \multirow{3}{*}{ Electric Motors } & Battery & \multirow{3}{*}{$0-15$} & \multirow{3}{*}{$<$ Mach 0.6} & \multirow{2}{*}{$\mathrm{N} / \mathrm{A}$} & $\mathrm{N} / \mathrm{A}$ & $0.1-1$ \\
\hline & Fuel Cell & & & & $\mathrm{N} / \mathrm{A}$ & $<1$ \\
\hline & $\begin{array}{l}\text { Solar-powered } \\
\text { photovoltaic cell }\end{array}$ & & & $\begin{array}{l}0.090 \text { (where the } \\
\text { reference fuel is H2) }\end{array}$ & $\mathrm{N} / \mathrm{A}$ & N/A \\
\hline \multirow{3}{*}{$\begin{array}{l}\text { Reciprocating } \\
\text { Engines }\end{array}$} & Two Stroke & \multirow{3}{*}{$0-9$} & \multirow{3}{*}{$<$ Mach 0.6} & $0.4-1.2$ & \multirow{2}{*}{$1-150$} & $0.8-2$ \\
\hline & Four Stroke & & & $0.3-0.4$ & & $0.4-1$ \\
\hline & Rotary & & & 0.35 & $15-70$ & N/A \\
\hline \multirow{4}{*}{ Gas Turbines } & Turbojet & \multirow[t]{2}{*}{$3-20$} & \multirow[t]{2}{*}{$>370 \mathrm{~km} / \mathrm{h}$} & \multirow[t]{2}{*}{$\mathrm{N} / \mathrm{A}$} & $\begin{array}{c}>4 \mathrm{kN} \\
(0.13-4.45 \mathrm{kN} \\
\text { for } \\
\text { target/cruise } \\
\text { missiles) }\end{array}$ & \multirow[t]{2}{*}{$\mathrm{N} / \mathrm{A}$} \\
\hline & Turbofan & & & & $\mathrm{N} / \mathrm{A}$ & \\
\hline & Turboprop & \multirow{2}{*}{$7-15$} & \multirow{2}{*}{$<$ Mach 0.6} & $0.3-0.5$ & \multirow{2}{*}{$>200$} & $3.5-4.8$ \\
\hline & Turboshaft & & & $\mathrm{N} / \mathrm{A}$ & & $4.3-9$ \\
\hline
\end{tabular}

Whilst each of these propulsion systems mentioned has its merits and demerits, which has been discussed extensively in references $[6,11,14,15]$, the focus of this paper is on the closed-cycle propulsion system. The reason for choosing the closed-cycle and especially the closed-Brayton cycle is because there is no valuable literature to the best of the author's knowledge that addresses the possibility of using a helium closed-cycle gas turbine for UAV application.

In this paper, the authors give a brief performance comparison of the different closedcycle engines with regards to UAV propulsion capability and also discusses the potentials of a closed-Brayton cycle, whilst highlighting various fluid media application and previous work by other researchers. The novelty of this paper is on the feasibility of helium closedcycle gas turbine UAV propulsion, highlighting both the performance and component design considerations for high altitude and high payload mission requirement. This work did not consider complex Computational fluid dynamics analysis (CFD) of the system behaviour as this will be covered in a future publication. Additionally, the scope of this paper does not cover the transient behaviour of the system as this will be covered in future work.

This paper is broken down into five sections, with Section 1 providing the background and rationale behind this work as well as the research novelty. Section 2 describes the closedcycle UAV propulsion and performance comparison of the closed-cycle engines as well as brief limitations encountered in the use of the cycles for the propose UAV mission. Section 3 provides a conceptual overview of the helium closed-cycle gas turbine for UAV application whilst showing both performance and component design characteristics. Section 4 provides a discussion of some results presented. In contrast, Section 5 gives a conclusion of the work whilst highlighting some of the research limitation and proposal for future work.

\section{The Closed-Cycle UAV Propulsion System}

The concept of using the closed-cycle engines to power UAVs is not new, as there are several studies on the feasibility of these type of propulsion systems for aircraft and UAVs which developed in the second world war [10]. Some of the closed-cycle propulsion systems reportedly used for UAV mission include the Rankine, Stirling and Brayton cycle [15]. Experience from both experimental and prototype models has shown that the 
closed-cycle engines are well suited for the UAV applications in several ways because of their advantage of containing fluid media, which eliminates the noise associated with the intake and exhaust systems. The high-power conversion efficiencies and power to weight ratio provided by the closed-cycle engines have demonstrated renewed interest in adapting the system for space power and UAV application. The outside air density does not have any significant effect on its output power/thrust requirement, and the operating pressure can be several times higher than the reciprocating engines which allow for a compact design.

A better contender to the closed-cycle engines in terms of low noise is the fuel-cell or battery-powered propulsion system. The closed-cycle engine is also suitable for high altitude UAV missions, as its operation is isolated from the effect of pressure drop occurring outside the system. Hence, it could benefit from improved efficiency at high altitude because of the gain in the heat exchanger temperature difference across the system. Although, there could be some adverse effect in terms of heat transfer, in general, the temperature difference at high altitude compensates for this shortfall providing an improvement in the cycle efficiency. Other benefits of the closed cycle engines are identified based on the various types discussed in Section 2.1 to Section 2.3.

In general, the major drawbacks to the use of the closed-cycle engines are its high heat rejection requirement and the additional weight from the heat exchangers and condenser, which could have its effect in a low altitude UAV mission. Other demerits have been highlighted for the individual closed-cycle propulsion systems. The differences between the Rankine, Stirling and Brayton cycles are their extra components, the cycle operations, and the fluid media.

To select any of the closed-cycle engines for a UAV, it must prove to have a competitive advantage over the other internal combustion engines. It must also be safe and have good flexibility in terms of fuel and working media selection. The working fluid flexibility is important because of mission requirements, especially for freezing conditions which the system must be designed to withstand. All closed-cycle engines compared to the opencycle ICE suffer from volume, weight, and capital cost disadvantages; hence, there is a need to ensure that any selected closed-cycle system demonstrates unique advantages to compete effectively with off the shelf ICEs. The consequence of increasing weight and engine complexity could partially offset the benefit of specific fuel consumption (SFC). For environmentally sensitive operations, the use of closed-cycle engines eliminates the open-cycle system. The closed-cycle engines align with the goal of resource conservation; however, the multiple heat exchangers make it more complex.

\subsection{The Rankine Closed-Cycle Engines}

The Rankine cycle is a vapour power cycle with constant pressure heat addition and rejection process. This cycle type is famous for power generation, and with a TRL less than 6 for aircraft application as a Besler engine, was the first successfully flown Rankine aircraft. The Besler engine operated on the Rankine cycle with a two-cylinder V-type engine that generated up to $150 \mathrm{HP}$. A steam boiler powered this semi-closed engine which flew 200 feet altitude and had a reduced noise operation compared with the reciprocating engines. It had a reciprocating turbine and a small condenser for cooling the steam. However, maintaining cooling was not a smooth task for this aircraft.

Although the first successfully flown Rankine occurred in 1933, its prospect quickly diminished due to several constraints associated with the Rankine cycle such as weight, lower efficiency compared with the competing engines and complex system integration with the airframe due to heat exchanger requirement. Additionally, its response to changes in throttle demand is relatively slow, and it has obvious cooling problems. These are among the many reasons that there are not many ongoing pieces of research that explore the potentials of steam Rankine cycle for UAVs mission, as known by the authors. However, rather than using steam, there are propositions to use organic fluid for this type of UAV altitude propulsion system $[10,15,16]$. Using organic fluid could potentially allow for high altitude operation as organic working fluids can handle colder temperature without 
freezing, and the heat required to power the system is incredibly low. One perceived advantage of this cycle with organic media is that a small high-pressure electric fluid pump could entirely replace its compressor as the pump work required is relatively small compared to other propulsion systems. This is because the compression process occurs in the liquid phase. Numerical analysis in reference [16] shows that high-temperature dry fluid with trans-critical cycles such as Toluene or cyclohexane could improve the system efficiency by $\sim 8 \%$.

Interestingly, organic fluid could achieve high efficiency with mid-low temperatures (between $100-200^{\circ} \mathrm{C}$ ). Operating an organic Rankine cycle (ORC) at temperatures above $300{ }^{\circ} \mathrm{C}$ could be limited by thermal stability [17]. The typical efficiency for this cycle would be between $20 \%$ and $27 \%$. One option to manage to weight issue for the Rankine cycle design is to ensure the small mass flow rate.

\subsection{The Stirling Closed-Cycle Engines}

The Stirling cycle engine is a closed-cycle heat engine that undergoes an isothermal compression and expansion process while rejecting heat at constant volume. This engine has the potential to operate at high efficiency and capable of utilising a variety of heat sources and fuels. Other advantages of the engine include low noise and vibration, especially for the free-piston Stirling engine, clean-burning and low emission, working fluid flexibility and high reliability. In 1986, McConaghy demonstrated the capability of using Stirling engines for a UAV mission. His $0.350 \mathrm{~kg}$ Stirling engine operating on helium was able to produce $0.025 \mathrm{~kW}$ of power to fly small UAV for $8 \mathrm{~min}$ [15]. Besides the McConaghy UAV test, the US Navy has also implemented several designs for UAV underwater operations [18].

Designing a Stirling engine could be overly complicated because of the dynamic behaviour of the mechanism and heat exchangers, as it is not easy to build a heat exchanger to operate continuously at high temperature. Increasing the working temperature and pressure increases the power density. However, the maximum temperature is constrained by material technology, which is currently within the range of $800-900{ }^{\circ} \mathrm{C}$. Good Stirling engine performance requires that the total gas volume be minimised. Maximum performance is also achieved with gases that have low specific heat, such that the maximum possible pressure increase is obtained for a given amount of heat input. Ideally, helium and hydrogen would be well suited for this application; however, the challenge will be how to manage seal leakage effectively $[19,20]$. One major difference between Stirling and the internal combustion engine is the rapid variation of power required and the instantaneous control of fuel supply to meet this demand. For the Stirling engines, there is usually a substantial time lag between fuel input and power output which make less competitive to the Brayton closed cycle. Another disadvantage would be the turbomachinery design, as its TRL is far below its Brayton closed-cycle counterpart. The Stirling engine, similar to any other reciprocating engine, can never be as light as a Brayton closed-cycle gas turbine but can compete only by achieving higher efficiency.

\subsection{The Brayton Closed-Cycle Engines}

The Brayton closed-cycle engines have the same thermodynamic process (isothermal compression and expansion) as the Brayton open-cycle (turbojet and turbofan). The difference is that the working media is isolated from the environment within a control volume and the additional component (heat exchanger) needed to cool the working fluid before recirculating it through the compressor. The closed-cycle gas turbine could either be coupled directly or indirectly to its heat source, giving it that flexibility in terms of heat source choice selection. Similar to other closed-cycle engines, it offers compactness and high reliability as there is no moving part in the machine in high temperature and reduction of thermal stresses. Another advantage is the flexibility in terms of working fluid selection, adapting to a variety of high energy and be able to operate efficiently over a wide power range [21]. 
The Brayton closed-cycle provides a better advantage for small UAV than the open cycle as the efficiency at low-pressure ratio favours the closed Brayton cycle (CBC). The Brayton closed-cycle has a lightweight advantage and higher efficiency in large size compared to other closed cycle engines. Hence, the CBC engine has many characteristics that are required for UAV missions. The system is suitable for a wide variety of missions, such as lunar, deep space, and earth orbit missions. In the 1950s, a program for Aircraft Nuclear Propulsion (ANP) was initiated by the Atomic Energy Commission in the US to redesign B-36 which was later renamed NB-36 [22-24]. By the 1960s, progress was made with both direct and indirect closed-cycle engines tested, using air as the working fluid [23]. Similarly, after extensive experimentation with different engines and transfer systems, the Soviet Engineers developed the Tupolev (Tu) Tu-95LAL and 34 more research flights completed between the 1950s and 1960s using the closed-cycle gas turbine technology [25]. Feasibility studies using closed-cycle gas turbine engines for UAVs have been documented; the study [15] evaluated the benefit of the closed-cycle gas turbine at high altitude performance, operation in polluted air environment using generic thermal heat sources.

The NASA-Lewis Research Centre developed a radioisotope closed-cycle gas turbine power generation unit in the 1960s, which achieved an output power between $2 \mathrm{~kW}$ and $10 \mathrm{~kW}[26,27]$. Similarly, the NASA Space Station Freedom selected a solar-powered CBC for space power system application. To this end, there are several pieces of research and development programs been deployed to show the technology readiness of the closed-cycle gas turbine in aerospace application $[15,24,28]$.

With the $\mathrm{CBC}$, the layout configuration can be arranged as such that the performance and thermo-economics are taken into consideration to get the right balance between system performance and capital cost. Interestingly, the working fluid selection could have an influence on the physical layout of the CBC engine [21]. Due to the self-contained nature of the CBC, almost all permanent gaseous working fluid can be used, however, with UAVs, unique criteria are considered such as thermal stability, inflammability, component material compatibility, and behaviour of fluid at freezing conditions. Several working fluids that can be considered range from monoatomic inert gases and mixtures, however, this paper will focus on the use of helium. Helium was selected due to its thermophysical properties, allowing for compact small UAV design, and would demonstrate high efficiency at a low-pressure ratio to compete with other propulsion systems.

The major challenge for the CBC design would be the heat source. As previously mentioned, this could be coupled directly or indirectly, and this can run on fuel ranging from nuclear fuel, natural gas, or solar. The most promising of these fuels are nuclear and solar; however, they both have their drawbacks. For this work, the authors have considered nuclear reactor coupled directly to the CBC.

While alternate propulsion systems may exhibit some of the attributes required for small UAV missions, this paper provides a balanced view of the merits and demerits of using helium closed-cycle gas turbine for UAV propulsion in terms of cycle performance and system design.

\section{The Helium Closed-Cycle Gas Turbine UAV Propulsion}

The helium closed-cycle gas turbine operates as a closed Brayton engine described in Section 2.3. The thermo-economic conceptual reason to use the helium closed-cycle gas is hinged on the need for an aircraft with a high payload, long-duration endurance, and unique missions for either low altitude high-speed penetrations or high-altitude mission.

To this end, the closed-cycle gas turbine discussed in this paper is coupled directly to a small, very high-temperature reactor (VHTR) cooled by helium working fluid with a core outlet temperature simulated between 700 and $950{ }^{\circ} \mathrm{C}$. With helium as the coolant and cycle working fluid, it brings several benefits such as chemical inertness, single-phase cooling and neutronic transparency, which makes reactivity effect with structural material low [29]. The choice of working fluid also has effects on the turbo set (compressor and turbine) in terms of the number of stages for the attainment of the required pressure ratio, 
high cycle efficiency and machine size. The conceptual system configuration shown in Figure 1 consists of a simple single-shaft arrangement connecting the turbo set, the heat sink (heat exchanger) and the VHTR.

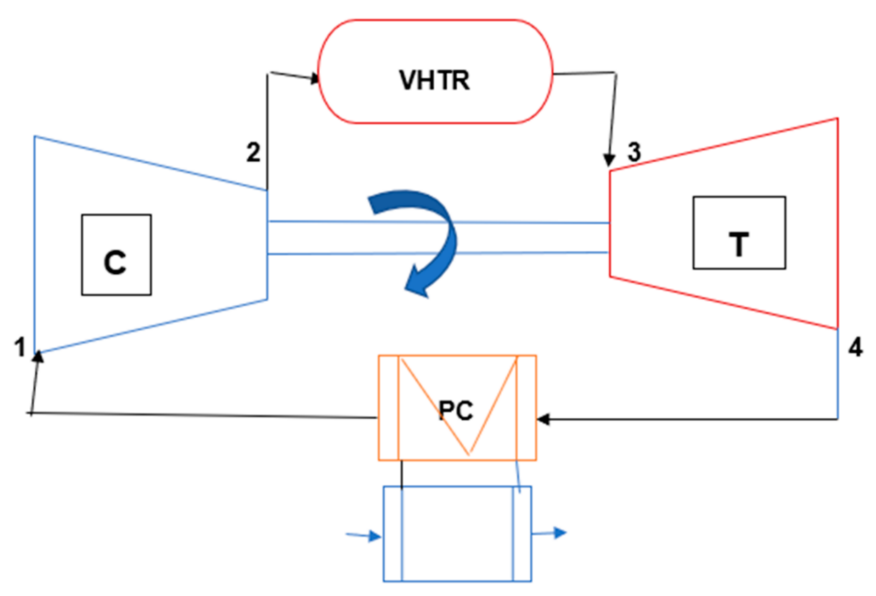

Figure 1. Helium closed-cycle gas turbine configuration.

Understandably, the VHTR could pose several regulation issues due to radiation hazards; however, the use of a unit shield and an inert gas such as helium could reduce the radiation effect to satisfactory levels both on the ground and inflight, even under reactor malfunction conditions. Evolutionary advances in nuclear propulsion-specifically in reactor compactness and shielding - makes the application of a shielded closed system possible and payload that could compete effectively with conventional reciprocating piston engines and open-cycle gas turbines at ranges above 90,000 feet. The simple single-shaft cycle arrangement described in Figure 1 is different from the ERAST (Environmental Research Aircraft and Sensor Technology) semi-closed cycle configuration discussed in reference [30].

The altitude, flight Mach number, output thrust and payload requirement have been specified in Table 2 to establish a benchmark for the proposed UAV mission, The mission requirement for the UAV is defined in terms of operational altitude, range, endurance and payload. Although the cycle arrangement is still in the conceptual stage, the goal of this work is to ascertain the feasibility of using the helium closed-cycle gas turbine for the mission requirement. Table 1 provides details of existing UAVs characteristics, and Figure 2 provides the performance trend of the existing UAVs.

Table 2. Baseline performance data.

\begin{tabular}{cc}
\hline Description & Values \\
\hline Cruise Altitude $(\mathrm{m})$ & 30,500 \\
Cruise Mach no & 0.7 \\
Take-off Mach no & 0.4 \\
Compressor pressure ratio & $2-5$ \\
Core outlet temperature $\left({ }^{\circ} \mathrm{C}\right)$ & $700-950$ \\
PC effectiveness $(\%)$ & 87 \\
Compressor efficiency $(\%)$ & 90 \\
Turbine efficiency $(\%)$ & 92 \\
Propeller efficiency $(\%)$ & 90 \\
\hline
\end{tabular}




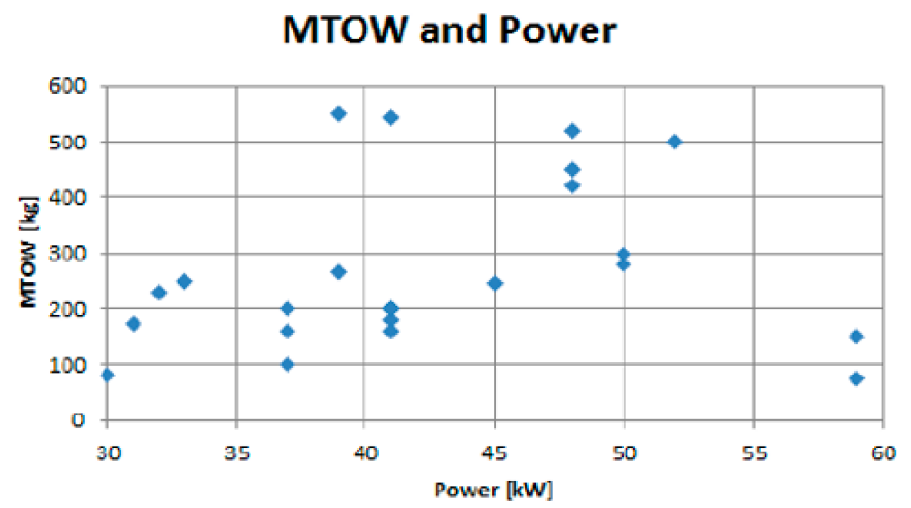

(a)

Range and Endurance

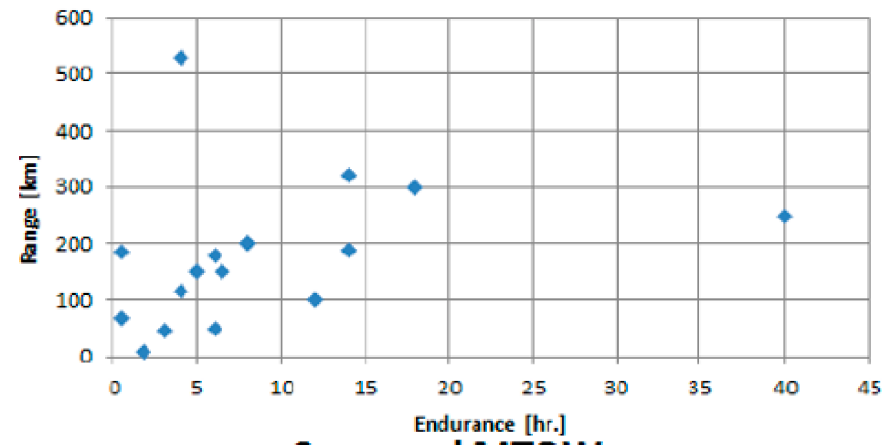

Span and MTOW

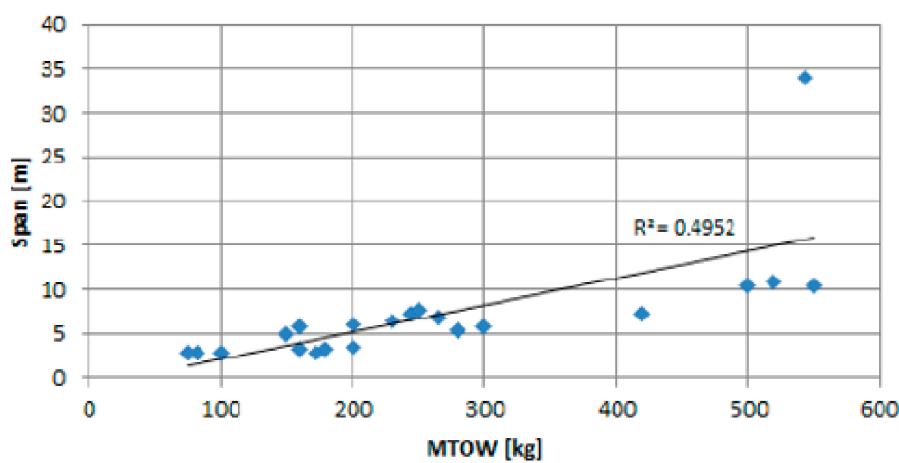

(c)

Endurance and MTOW

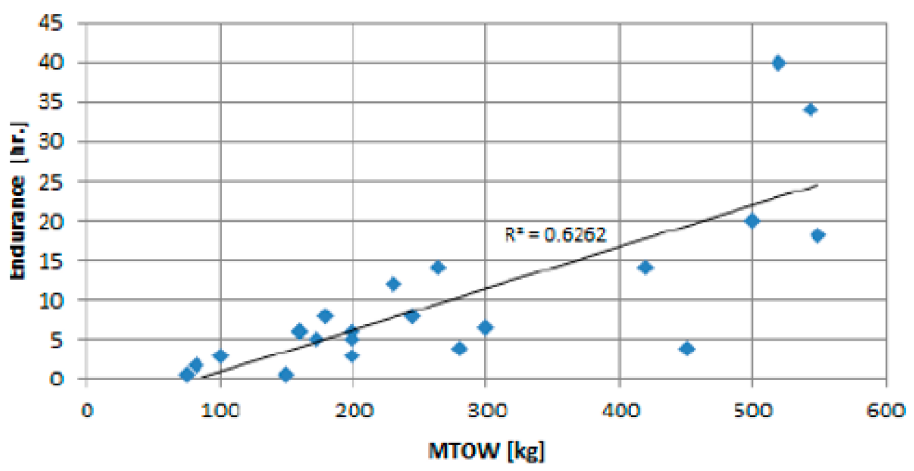

(d)

Figure 2. Performance trend of existing unmanned aerial vehicles (UAVs) (a) Maximum take-off weight against power (b) flight range against endurance (c) Span against maximum take-off weight (d) endurance against maximum take-off weight [1,12]. 
To this end, a pressure ratio of 4 was selected for the gas turbine to keep the turbo set weight and size within reasonable values. For a simple helium closed-cycle gas turbine, an increase in pressure ratio peaks between 4 and 6 , from whence the cycle performance begins to retrogress. The core outlet temperature of $800{ }^{\circ} \mathrm{C}$ was chosen to manage the cooling requirement of the conceptual design and heat exchanger size. An unlimited range would offer an attractive and competitive UAVs requirement for today. However, there are constraints to achieving an unlimited range proposition which is linked to the fuel load and system weight. One benefit of the closed-cycle system is the freedom in selecting the cycle pressures and temperatures as this would allow for tailoring and system adaptability to mission-specific criteria.

\subsection{Engine Model Development}

A comprehensive engine component model and thermodynamic calculations to define the system performance was accomplished with an in-house tool developed by the authors, which is described in details in reference [31]. The overall performance of the system is a function of its components based on the baseline characteristics presented in Table 1. Changing the operating variables at different altitude describes the off-design model and component matching procedure. The working fluid model implemented in the in-house tool is correlated with Cool Prop library [32].

\subsubsection{Turbomachinery Model}

Dimensionless parameters describe the behaviour of the turbomachinery component. The performance characteristics are usually plotted as pressure ratio against dimensionless or corrected mass flow $(C M F)$, corrected speed $(C S)$ and corrected enthalpy $(C H)$. The following expressions represent the dimensionless parameters:

$$
C M F=\left(\frac{W \sqrt{\theta}}{\delta} \times \sqrt{\frac{R}{\gamma}}\right), C S=\left(\frac{N}{\sqrt{\theta R \gamma}}\right), C H=\left(\frac{\Delta H}{\sqrt{\theta R \gamma}}\right)
$$

where,

$$
\theta=\left(\frac{T}{T_{r e f}}\right), \delta=\frac{P}{P_{r e f}}
$$

The temperature at the exit of the compressor is obtained from the isentropic relationship between inlet temperature, isentropic efficiency, pressure ratio and the ratio of specific heats, given by the expression:

$$
T_{\text {Cout }}=T_{\text {Cin }}+\frac{T_{\text {Cin }}}{\eta_{c}}\left[\left(\frac{P_{\text {Cout }}}{P_{\text {Cin }}}\right)^{\left(\frac{\gamma-1}{\gamma}\right)}-1\right]
$$

where the compressor discharge pressure is derived from the given pressure ratio:

$$
P R_{c}=\frac{P_{c_{\text {out }}}}{P_{c_{\text {in }}}}=f(C M F, C S)
$$

The Non-Dimensional Compressor Work $(N D C W)$ is derived as:

$$
N D C W=\frac{C W}{\delta \sqrt{\theta}}=f(C M F, C S)
$$

where the Compressor Work $(\mathrm{CW})$, is a product of the mass flow rate, specific heat capacity at constant pressure and the overall temperature rise in the compressor.

$$
C W=W C_{P_{\text {out }}} T_{\mathcal{C}_{\text {out }}}-W C_{P_{\text {in }}} T_{\mathcal{c}_{\text {in }}}
$$


To solve Equations (1)-(5), the input data is obtained from the design point inlet conditions and compressor performance map.

Similar to the compressor, the performance characteristics of the turbine is described by several dimensionless parameters. The non-dimensional parameters defined for the compressor is similar to the turbine. The input data at the design point are the turbine inlet conditions (mass flow rate, temperature, and pressure), and component efficiency.

The temperature at the outlet of the turbine is obtained from the following expression:

$$
T_{\text {tout }}=T_{\text {tin }}-\left(T_{\text {tin }} \times \eta_{t}\right)\left[1-\left(\frac{P_{\text {tout }}}{P_{\text {tin }}}\right)^{\left(\frac{\gamma-1}{\gamma}\right)}\right]
$$

The Non- Dimensional Turbine Work (NDTW) can be obtained from:

$$
N D T W=\frac{T W}{\delta \sqrt{\theta}}=f\left(\left(\frac{P_{\text {tout }}}{P_{\text {tin }}}\right), C S\right)
$$

where $T W$ is the turbine work, which is expressed as:

$$
T W=W C_{P_{\text {out }}} T_{t_{\text {out }}}-W C_{P_{\text {in }}} T_{t_{\text {in }}}
$$

Implementing system components pressure losses will mean that the turbine pressure ratio becomes:

$$
P R_{t}=\frac{P_{c_{\text {out }}}}{P_{c_{\text {in }}}}
$$

The overall compressor and turbine design assumed a free vortex velocity distribution with constant outer diameter annulus configuration. The annulus area for the turbo-set inlet and outlet geometry is given as:

$$
A=\frac{W \sqrt{T}}{Q_{o} K_{b} P}=\frac{\pi D_{m}^{2}}{4}
$$

where,

$K_{b}=$ blockage factor

$Q_{0}=$ Non-dimensional mass flow

The number of stages is given by:

$$
\text { Number of Stages }=\frac{C_{p} \Delta T}{\Delta h}
$$

The stage loading and flow coefficient are given as:

$$
\begin{gathered}
\text { Stage load }=\frac{C_{p} \Delta T}{U_{m}^{2}} \\
\text { Stage flow coefficient }=\frac{V_{a}}{U_{m}}
\end{gathered}
$$

The length of the turbo-set is calculated using Sagerser empirical relationship such that compressor length is given as [33]:

$$
L_{c}=D_{m} \times\left[\left(0.2+\left[\left(0.234-\left(0.218 * h u b \_t i p \_r a t i o\right)\right)\right] \times N_{S}\right)\right]
$$

And the turbine length is given as:

$$
\begin{aligned}
L_{T}=N_{S}\left[\left(\frac{\overline{D_{t}}-\overline{D_{h}}}{0.96 \times h u b_{-} \text {tip }}\right)_{\text {rotor }}+\left(\frac{\overline{D_{t}}-\overline{D_{h}}}{0.96 \times h u b_{-} \text {tip }}\right)_{\text {stator }}\right. \\
\left.+\left(2 N_{S}-1\right)\left(0.4 \times \frac{\overline{D_{t}}-\overline{D_{h}}}{0.96 * \text { hub tip }}\right)_{\text {rotor }}\right]
\end{aligned}
$$




\subsubsection{Precooler Heat Exchanger Model}

The precooler is modelled as a heat exchanger using the E-NTU method, and a counterflow shell and tube configuration was assumed. The $\varepsilon$-NTU method was used since the inlet condition (temperature and pressure) of the fluid stream can be easily obtained and simplifies the iteration involved in predicting the performance of the flow arrangement. This method is fully described in references $[34,35]$. The approach also assumes that the heat exchanger effectiveness is known, and the pressure losses are given.

Therefore, the effectiveness of the heat exchanger is the ratio of the actual heat transfer rate to the thermodynamically limited maximum heat transfer rate available in a counter flow arrangement.

$$
\varepsilon=\frac{Q_{\text {actual }}}{Q_{\max }}=\frac{C_{\text {hot }}\left(T_{\text {hotin }}-T_{\text {hotout }}\right)}{C_{\min }\left(T_{\text {hotin }}-T_{\text {coldin }}\right)}=\frac{C_{\text {cold }}\left(T_{\text {coldout }}-T_{\text {coldin }}\right)}{C_{\min }\left(T_{\text {hotin }}-T_{\text {coldin }}\right)}
$$

where $C_{\min }$ and $C_{\max }$ are the smaller and larger of the two magnitudes of $C_{\text {hot }}$ and $C_{\text {cold }}$

$$
\begin{gathered}
C_{\text {hot }}=\left(W C_{P}\right) \text { hot fluid Stream, } C_{\text {cold }}=\left(W C_{P}\right) \text { cold fluid Stream } \\
\qquad C_{\text {min }}=\left\{\begin{array}{l}
C_{\text {hot }} \text { for } C_{\text {hot }}<C_{\text {cold }} \\
C_{\text {cold }} \text { for } C_{\text {cold }}<C_{\text {hot }}
\end{array}\right.
\end{gathered}
$$

For counterflow shell and tube heat exchangers, number of transfer unit (NTU) is given by:

$$
N T U=\frac{L O G_{e}\left[\frac{2-\varepsilon\left(1+C^{*}-\eta_{H e x}\right.}{2-\varepsilon\left(1+C^{*}+\eta_{H e x}\right.}\right]}{\eta_{H e x}}
$$

where

$$
\begin{gathered}
C^{*}=\text { Capacity rate ratio }=\frac{C_{\min }}{C_{\max }} \\
\eta_{\text {Hex }}=\left(C^{* 2}+1\right)^{0.5}
\end{gathered}
$$

Assuming pressure losses, then the exit pressure at design point is given as:

$$
P_{\text {out }}=P_{\text {in }}(1-\Delta P)
$$

where $\Delta P$ is the percentage of pressure loss specified as the input for each component. It is important to emphasis that the precooler utilizes air cooling. The code was modelled to have the working fluid temperature after pre-cooling process equal to the compressor entry temperature; although, in a real scenario, the temperature may vary a little.

\subsubsection{The Thrust Converter System}

The purpose of the thrust converter is to translate the torque produced by the gas turbine into thrust.

Thus,

$$
P_{r}=V_{\infty} \times \text { Thrust }
$$

where,

$$
P_{r}=\text { Power required } V_{\infty}=\text { Free stream velocity }
$$

The thrust converter efficiency is given as:

$$
\eta_{t h r}=\frac{V_{\infty} \times \text { Thrust }}{P_{r}}
$$

And thrust for steady flight is a function of weight, drag and lift coefficient given as:

$$
\text { Thrust for steady flight }=\frac{C D}{C L} \times \text { Weight }
$$




\subsubsection{Weight Model}

A significant design goal is to minimise the propulsion system weight. Hence the overall system weight is an aggregate of the component weight.

$$
\text { Weight }_{\text {engine }}=\text { Weight }_{C}+\text { Weight }_{T}+\text { Weight }_{V H T R}+\text { Weight }_{P C}
$$

The weight of the turbomachinery component is estimated according to the NASA weight analysis of turbine engine model [36] and the precooler weight model as described in the work of Kakac and Liu [34] and Shan and Sekulic [35]. A breakdown of the weight contribution shows that the significant contributors to the system are the nuclear reactor and shield, and the heat sink.

\subsubsection{Endurance and Range}

Endurance is the maximum length of time the UAV can spend in cruise, which is a function of the lift, drag, system weight and fuel load. The Breguet range equation was used to calculate endurance and range [37], which depends whether the thrust is propeller or jet driven. The relationship is expressed as:

$$
\begin{aligned}
& \text { Range }=\frac{\eta_{\text {thr }}}{W_{f}} \times \frac{C D}{C L} \times \ln \frac{\text { Takeoff Weight }}{\text { Landing Weight }} \\
& \text { Endurance }=\frac{\eta_{t h r}}{W_{f}} \times \sqrt{2 \rho S} \frac{C L^{1.5}}{C D} \times\left(\text { Landing Weight }{ }^{-0.5}-\text { Takeoff Weight }^{-0.5}\right)
\end{aligned}
$$

\section{Discussion}

\subsection{System Performance}

The helium closed-cycle gas turbine looks suitable for UAV missions. It is compact, efficient and offers high reliability since it requires only one rotating equipment (turbo set). The choice of helium as a working fluid enhances the overall system design, and the operating envelope does not adversely affect the working fluid. The top-level requirement of high payload, high altitude, long-endurance, and range are representative of the mission requirements which could be reasonably expected but sufficiently stringent to test the real application of the closed-cycle gas turbine system for UAV propulsion.

The system mass flow rate, temperature, and pressure, as well as component characteristic, were simulated for targeted thrust and system performance based on pressure ratio, turbine entry temperature (TET), and altitude variation. The choice of mass flow has a direct relationship with the thrust, the power required, weight and system size. In the parametric assessment, a fixed mass flow of $50 \mathrm{~kg} / \mathrm{s}$ was chosen as a representative for a thrust and payload requirement. The mass flow value can be optimised in relationship with TET to obtain a lightweight UAV. The proposal to use a single-shaft arrangement also reduces the complexity of weight. The payload estimate refers to equipment for which the UAV provides platform and transportation. In this context, the payload is a measure of the size, weight, and power available to perform take-off, fly around and landing.

Figure 3 shows the strong relationship between specific fuel consumption and the TET and pressure ratio. At take-off, a simultaneous increase in the TET from 700 to $950{ }^{\circ} \mathrm{C}$, and pressure ratio both decreases the SFC requirement. However, there is a limit for an optimum UAV mission requirement considering the implication of size for pressure ratio and the cooling need for both turbine and the precooler heat exchanger. A temperature between 700 and $800{ }^{\circ} \mathrm{C}$ seems to be conservative to high payload mission as the TET have a direct effect on the power required and thrust. 


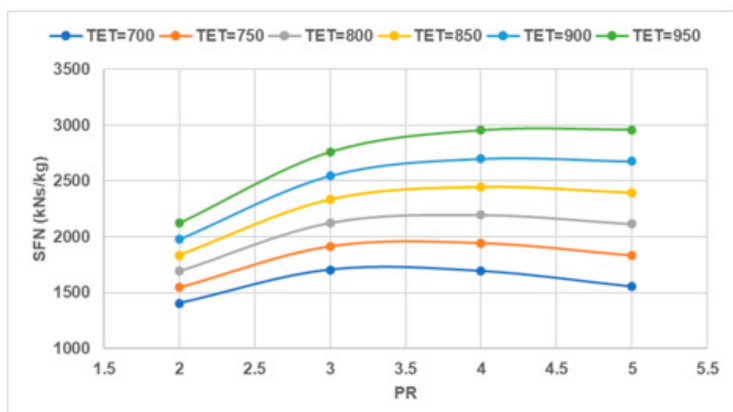

(a)

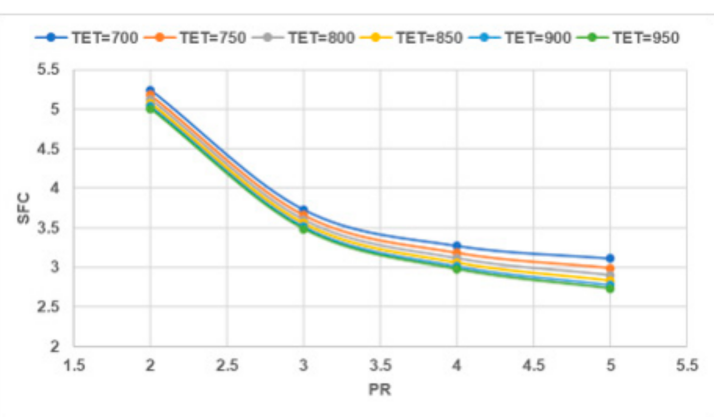

(b)

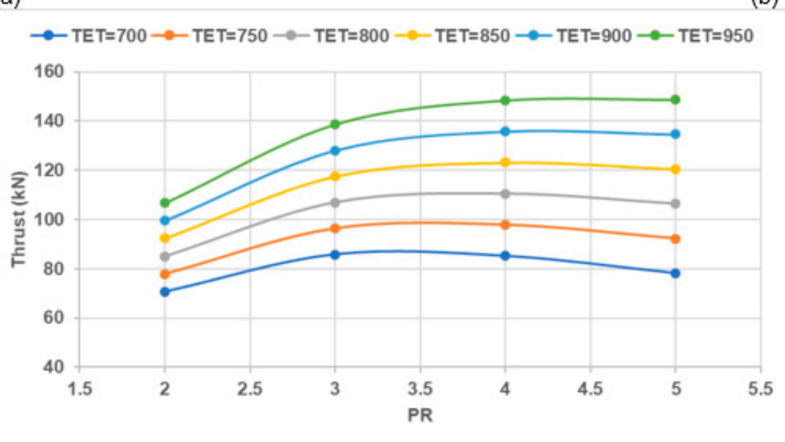

(c)

Figure 3. Parametric analysis of cycle at Maximum Take-off Thrust, Weight and Mach number 0.4 at different turbine entry temperatures (a) specific thrust against pressure ratio, (b) specific fuel consumption against pressure ratio (c) Thrust against pressure ratio.

The parametric study shows the system performance peak pressure ratio of 4 and a conservative TET of $800^{\circ} \mathrm{C}$ was chosen as the final baseline for the analysis. A pressure ratio of 4 was selected for the gas turbine to keep the turbo set weight and size within reasonable values. An increase in power density for the helium closed-cycle gas turbine provides a small system size and less cycle pressure losses compared with other propulsion systems. However, a maximum take-off thrust of $110 \mathrm{kN}$ at a TET of $800^{\circ} \mathrm{C}$ was chosen due to cooling requirement and heat sink design constraints. In the preliminary design, one-third of the pumping power is assigned to the reactor and one-sixth to the precooler. With much high thermal conductivity and permissible flow velocity; helium heat exchangers are compact. The problem with Ranking rejection at almost constant temperature is in contrast with the closed-cycle gas turbine as heat is rejected over a wide range of temperature. The success of the closed-cycle application for UAV is tied to the heat sink. The radiator area should be compact and efficient at rejecting the waste for recycling of the helium working fluid into the compressor. In the preliminary analysis, pressure losses were not considered.

Table 3 shows the system performance at 30,000 $\mathrm{m}$ and a Mach number of 0.7.

Table 3. System performance at 30,000 m.

\begin{tabular}{cc}
\hline Descriptions & Value \\
\hline Altitude $(\mathrm{m})$ & 30,000 \\
Mach number & 0.7 \\
Thrust $(\mathrm{kN})$ & 74.847 \\
Specific fuel consumption $(\mathrm{SFC})$ & 3.03 \\
Turbine entry temperature TET $\left({ }^{\circ} \mathrm{C}\right)$ & 822 \\
\hline
\end{tabular}

The control at different thrust requirement can be easily achieved with pressure level control, heat source and by-pass control. For most cases, pressure level control is performed at almost constant SFC and a constant temperature in all component. Parametric sizing and weight estimates were made for the turbomachinery and precooler and reactor. 


\subsection{Component Design Constraints}

\subsubsection{Turbo Set}

The turbo set design relies on the technology available mainly in the area of the performance, material, design and fabrication method. The choice of the turbo set (compressor and turbine) type, and pressure ratio is an important design consideration for simplicity and cost reduction. In the proposed model, a compressor pressure ratio between 3 and 5 seems to be a modest value because of the design difficulties associated with the thermodynamic behaviour of the helium and the direct effect of the pressure ratio to compressor size. The relative engine length tends to increase in a regular manner with pressure ratio. However, the low molecular weight of helium causes a high acoustic velocity, hence, could eliminate the Mach number constraints on the aerodynamic design of the turbo-set components. Additionally, the enthalpy and specific heat change would allow for high blade velocity $(\mathrm{m} / \mathrm{s})$ design to reduce the number of stages. The challenge then becomes how to induce the highest possible velocities that the blade would allow since the stage loading factor is inversely proportional to the square of the blade velocity.

Designing for a low noise propulsion system, one would prefer to slow the rotational speed of the shaft while maintaining power so that mechanical noise and propeller tip velocity are both decreased. The helium compressors design for the closed-cycle propulsion is characterized by high hub-to-tip ratios, low aspect ratios and small blade height. The overall design of the compressor uses a free vortex velocity distribution with constant inner diameter for all stages.

The properties of the helium would also affect the turbine design characteristics, such as the compressor. Since it is desirable to have a high blade speed as possible to reduce the number stages, the problem will be on the turbine first stage due to the rotor blade temperature will be at a maximum. The overall design of the turbine is based on free vortex with constant mean diameter for all stages. With a turbine entry temperature between 700 and $850{ }^{\circ} \mathrm{C}$, the turbine blade cooling requirement could be easily managed, and the blade life could be met with a bleed flow of $\sim 1 \%$.

Another design challenge will be on the seal to reduce leakage, accommodate nonuniformities between mating parts and to accommodate differential expansion and thermal distortion. The use of bearing stub shafts at each rotor end could eliminate unnecessary weight while maintaining bending stiffness. Table 4 shows the design characteristics for both the compressor and turbine.

Table 4. Turbo set design characteristics.

\begin{tabular}{ccc}
\hline Description & Compressor & Turbine \\
\hline Inlet temperature $\left({ }^{\circ} \mathrm{C}\right)$ & 300 & 800 \\
Inlet pressure $(\mathrm{kPa})$ & 303.975 & 303.975 \\
Mass flow $(\mathrm{kg} / \mathrm{s})$ & 50 & 50 \\
Rotational speed $(\mathrm{rpm})$ & 16,000 & 16,000 \\
Pressure ratio & 4 & 4 \\
Number of stages & 4 & 2 \\
Um $(\mathrm{m} / \mathrm{s})$ & 302 & 302 \\
Temperature ratio & 1.81 & 1.65 \\
Length $(\mathrm{m})$ & 0.53 & 0.29 \\
Relative Weight & 0.6 & 0.7 \\
\hline
\end{tabular}

\subsubsection{Reactor}

The reactor module comprises of the reactor, the primary circulator, the reactor shutdown cooling system with the main cylindrical section housed in the reactor vessel. The design goal will be to minimise the reactor volume for a given reactor power. However, this is limited to temperature materials, heat transfer rates and radiation considerations. 
To design a compact reactor for the UAV, one must also consider how to manage the fuel burn-up, the fission products and elements.

The major single item weight of the reactor heat source is the weight of the reactor shield, which is required to protect against the damaging effects of the nuclear radiation. Although for a given reactor, the shield weight per unit power output tends to decrease as the reactor output power increases, this would have an impact on the size of the reactor and could add another constraint for a lightweight design. With new technology available, there has been consistent progress made with compact reactor design and reduction in the shield weight. A significant success can be achieved with justifiable efforts aimed at minimising the weight penalty of the reactor and the overall system.

\subsubsection{Precooler}

The challenge with closed-cycle cycle system is the high heat sink requirement. This is an addition to drag and get worse at the climb phase. The design of the heat sink is critical to the success of the helium closed-cycle gas turbine. An involute spiral multipass counter-cross flow heat exchanger can be used to achieve efficient cooling. The cold side inlet Mach number and the number of tubes are essential factors to consider when designing the precooler. A longer tube design will result in additional weight, and a smaller tube diameter will perform better thermally. The heat rejection effectiveness improves for the closed-cycle propulsion system with altitude because of increasing temperature differentials.

\section{Conclusions}

The feasibility study on the helium closed-cycle gas turbine shows it could be suitable for high payload, low noise, and high attitude mission requirement. The design requirement differs considerably from the ICEs, and other UAV closed-cycle propulsion systems. However, the major drawback to the application of the helium closed-cycle propulsion system includes weight associated with the reactor, and reactor shield, the heat rejection and obvious stringent certification issues.

The goal of achieving a lightweight propulsion system is hinged on the system configuration and parameter selection. The preliminary assessment carried out showed that a pressure ratio between 3 and 5 and TET between 700 and $800{ }^{\circ} \mathrm{C}$ would give an optimum system performance while considering all possible constraints such as weight, size, material and cooling requirement. The baseline representative assessment with a pressure ratio of 4 and TET of 800 at MTOW and thrust shows a compact turbo set with four stages of axial compression and two stages of the expansion to achieve a thrust of $110 \mathrm{kN}$. The value may seem overly exaggerated since pressure losses and other component losses were not considered during the assessment.

The scope of this paper does not cover a detailed geometry design and transient behaviour of the system as this will be covered in future work, as well as CFD assessment.

Author Contributions: Conceptualization, E.O.O. and A.G.-B.; methodology, E.O.O.; software, E.O.O. and A.G.; validation, E.O.O., A.G.-B. and T.N.; formal analysis, E.O.O.; investigation, E.O.O.; resources, A.G.-B., and T.N.; data curation, E.O.O.; writing-original draft preparation, E.O.O.; writing-review and editing, E.O.O.; visualization, E.O.O.; supervision, T.N.; project administration, A.G.-B.; funding acquisition, A.G.-B. All authors have read and agreed to the published version of the manuscript.

Funding: This research received no external funding.

Institutional Review Board Statement: Not Applicable.

Informed Consent Statement: Not Applicable.

Data Availability Statement: Not Applicable.

Conflicts of Interest: Authors confirm that there is no conflict of interest with regards to publishing this article. 


Nomenclature
Notation
$A$
CD
CL
$C H$
$C_{p}$
$C S$
$C W$
$D_{m}$
$K_{b}$
$L_{c}$
$L_{T}$
$N_{s}$
$N D C W$
$N D T W$
P
$P_{r}$
S
SFC
T
TET
TW
$\mathrm{U}_{\mathrm{m}}$
$V_{\infty}$
W
$W_{f}$
$\rho$
$\eta_{t h r}$
$\Delta_{h}$
$\Delta_{P}$
$\Delta T$
Abbreviations
ICE
CMF
C
CBC
CFD
DP
OD
ORC
PC
PR
SF
T
TRL
UAV
VHTR
Subscript
$c$
$t$

Flow annulus area $\mathrm{m}^{2}$

Drag coefficient

Lift coefficient

Corrected enthalpy

Specific heat capacity, J/kgK

Corrected speed

Compressor work, W

Mean diameter, $\mathrm{m}$

Blockage factor

Compressor length, $\mathrm{m}$

Turbine length, $\mathrm{m}$

Rotational speed (rpm)

Non-dimensional compressor work

Non-dimensional turbine work

Pressure, $\mathrm{Pa}$

Power required, $\mathrm{kW}$

Wing platform area, $\mathrm{m}^{2}$

Specific fuel consumption

Temperature, ${ }^{\circ} \mathrm{C}$

Turbine entry temperature, ${ }^{\circ} \mathrm{C}$

Turbine work, $\mathrm{W}$

Mean speed $\mathrm{m} / \mathrm{s}$

Free stream velocity, $\mathrm{m} / \mathrm{s}$

Mass flow $\mathrm{kg} / \mathrm{s}$

Fuel flow, kg/s

Density, $\mathrm{kg} / \mathrm{m}^{3}$

Propeller efficiency

Enthalpy change

Pressure change

Temperature change

Internal Combustion Engine

Corrected Mass Flow

Compressor

Closed Brayton cycle

Computational fluid dynamics

Design point

Off-design

Organic Rankine cycle

Precooler

Pressure ratio

Scaling factor

Turbine

Technology readiness level

Uncrewed/unmanned aerial vehicles

Very high-temperature reactor

Compressor

Turbine

\section{References}

1. Griffis, C.; Wilson, T.; Schneider, J.; Pierpont, P. Unmanned Aircraft System Propulsion Systems Technology Survey. Washington, DC, USA, 2009. Available online: https:/ / commons.erau.edu/publication/72\%0D (accessed on 25 June 2020).

2. Cox, T.H.; Somers, I.; Fratello, D.J.; Nagy, C.J.; Schoenung, S.; Shaw, R.J.; Skoog, M.; Warner, R. Earth Observations and the Role of UAVs: A Capabilities Assessment. Washington, DC, USA, 2006. Available online: https://www.nasa.gov/centers/dryden/pdf/ 175939main_Earth_Obs_UAV_Vol_1_v1.1_Final.pdf (accessed on 4 August 2020).

3. Intelligence Morder. Unmanned Aerial Vehicle Market-Growth, Trends, and Forecast. Hyderabad. 2017. Available online: https:/ / www.mordorintelligence.com/industry-reports/uav-market (accessed on 4 August 2020).

4. Rodgers, C. Turbofan Design Options for Mini UAV's. In Proceedings of the 37th AIAA/ASME/SAE/ASEE Joint Propulsion Conference and Exhibit, Salt Lake City, UT, USA, 8-11 July 2001; pp. 1-12.

5. Andrei, I.C.; Niculescu, M.L.; Pricop, M.V.; Cernat, A. Study of the Turbojet Engines as Propulsion System for the Unmanned Aerial Vehicles. In Proceedings of the 18th International Conference of Scientific Research and Education in the Air Force, Aalborg, Denmark, 8-9 September 2016; pp. 2247-3137. [CrossRef]

6. Osenar, P.; Sisco, J.; Reid, C. Advanced Propulsion for Small Unmanned Aerial Vehicles-The Role of Fuel Cell-Based Energy Systems for Commercial UAVs; Protonex Technology Corporation: Southborough, MA, USA, 2017. 
7. González-Espasandín, Ó.; Leo, T.; Navarro, E. Fuel Cells: A Real Option for Unmanned Aerial Vehicles Propulsion. Sci. World J. 2014, 2014, 1-12. [CrossRef] [PubMed]

8. Tacconi, J.; Visser, W.; Verstraete, D. Potential of Semi-Closed Cycles for UAV Propulsion. In Proceedings of the ASME Turbo Expo 2019: Turbomachinery Technical Conference and Exposition, Phoenix, AZ, USA, 17-21 June 2019; pp. 1-12.

9. Tacconi, J.; Visser, W.P.J.; Verstraete, D. Multi-objective optimisation of semi-closed cycle engines for high-altitude UAV propulsion. Aeronaut. J. 2019, 123, 1938-1958. [CrossRef]

10. Harper, A.D.; Jansen, J.S. Closed Brayton cycle engine application to emerging unmanned underwater vehicle missions. In Turbo Expo: Power for Land, Sea, and Air; no. 90-GT-307; American Society of Mechanical Engineers: New York, NY, USA, 1990; Volume 79061.

11. Adamski, M. Analysis of propulsion systems of unmanned aerial vehicles. J. Mar. Eng. Technol. 2017, 16, 291-297. [CrossRef]

12. Marcellan, A. An Exploration into the Potential of Microturbine based Propulsion Systems for Civil Unmanned Aerial Vehicles. Master's Thesis, Delft University Of Technology, Delft, The Netherlands, 2015.

13. Parsch, A. Boeing/Insitu ScanEagle. 2009. Available online: http://www.designation-systems.net/dusrm/app4\%0A/scaneagle. html (accessed on 20 May 2020).

14. Gundlach, J. Designing Unmanned Aircraft Systems: A Comprehensive Approach; AIAA: Salt Lake City, UT, USA, 2012.

15. Hays, T.C.; Arena, A.S.J. Feasibility Study of Closed Cycle Propulsion for Unmanned Aerial Systems. In Proceedings of the AIAA Atmospheric Flight Mechanics Conference, Dallas, TX, USA, 22-26 June 2015; pp. 1-16.

16. Zhang, J.; Qin, K.; Li, D.; Luo, K.; Dang, J. Potential of Organic Rankine Cycles for Unmanned Underwater Vehicles. Energy 2020, 192, 1-18. [CrossRef]

17. Wang, D.; Ling, X.; Peng, H.; Liu, L.; Tao, L. Efficiency and optimal performance evaluation of organic Rankine cycle for low grade waste heat power generation. Energy 2013, 50, 343-352. [CrossRef]

18. Oelrich, C.; Riddell, F.R. Evaluation of Potential Military Applications of Stirling Engines; Institute for Defense Analyses: Alexandria, VA, USA, 1988.

19. Osigwe, E.O.; Pilidis, P.; Nikolaidis, T.; Igbong, D. Risk Assessment on Working Fluid Selection for Closed-Cycle Gas Turbine Systems. In Proceedings of the ASME 2019 Power Conference, Salt Lake City, UT, USA, 15-18 July 2019.

20. Harrison, J. Small and Micro Combined Heat and Power (CHP) Systems. In Advanced Design, Performance, Materials and Applications; Woodhead Publishing Limited: Cambridge, UK, 2011.

21. Osigwe, E.O.; Gad-Briggs, A.; Pilidis, P.; Nikolaidis, T.; Sampath, S. Effect of working fluid on selection of gas turbine cycle configuration for Gen-IV nuclear power plant system. In Proceedings of the International Conference on Nuclear Engineering (ICONE), Tsukuba, Japan, 19-24 May 2019; p. 9.

22. McDonald, F. Gas turbine power plant possibilities with a nuclear heat source. Closed and open cycles. In Turbo Expo: Power for Land, Sea, and Air; American Society of Mechanical Engineers: New York, NY, USA, 1990; Available online: http:/ / www.scopus. com/inward/record.url?eid=2-s2.0-0025257997\&partnerID=40\&md5=386ba7cf52fcd800a0b63b884532e1e0 (accessed on 3 May 2016).

23. Wheeler, A. A Brief History of Nuclear Airplanes. Mentalfloss. 2013. Available online: http://mentalfloss.com/article/53184/ brief-history-nuclear-airplanes (accessed on 26 October 2015).

24. Narayanan, K.; Dessanti, B. Brayton Cycle Conversion for Space Solar Power. In Proceedings of the 48th AIAA/ASME/ASEE Joint Propulsion Conference and Exhibit, Atlanta, GA, USA, 30 July-1 August 2012; pp. 1-11.

25. Colon, R. Soviet Experimentation with Nuclear Powered Bombers. 2015. Available online: http:/ /www.aviation-history.com/ articles/nuke-bombers.htm (accessed on 26 October 2015).

26. Baggenstoss, W.G.; Ashe, T.L. Mission Design Drivers for Closed Brayton Cycle Space Power Conversion Configuration. J. Eng. Gas Turbines Power 1992, 114, 721-726. [CrossRef]

27. Klann, J.; Wintucky, W. Status of the 2- to 15-KWe Brayton ower System and Potential Gains from Component Improvements; Society of Automotive Engineers: Boston, MA, USA, 1971.

28. Ribeiro, G.B.; Filho, F.A.B.; Guimarães, L.N. Thermodynamic analysis and optimization of a Closed Regenerative Brayton Cycle for nuclear space power systems. Appl. Therm. Eng. 2015, 90, 250-257. [CrossRef]

29. Osigwe, E.O.; Gad-Briggs, A.; Nikolaidis, T.; Pilidis, P.; Sampath, S. Performance Analyses and Evaluation of $\mathrm{CO}_{2}$ and $\mathrm{N}_{2}$ as Coolants in a Recuperated Brayton Gas Turbine Cycle for a Generation IV Nuclear Reactor Power Plant. J. Nucl. Eng. Radiat. Sci. 2020, 6. [CrossRef]

30. Bettner, J.L.; Blandford, C.; Rezy, J. Propulsion System Assessment for Very High Altitude UAV Under ERAST; National Aeronautics and Space Administration: Indianapolis, IN, USA, 1995.

31. Osigwe, E.O.; Pilidis, P.; Nikolaidis, T.; Sampath, S. Gas Turbine Arekret-Cycle Simulation Modeling for Training and Educational Purposes. J. Nucl. Eng. Radiat. Sci. 2019, 5, 041207. [CrossRef]

32. Bell, I.H.; Wronski, J.; Quoilin, S.; Lemort, V. Pure and Pseudo-pure Fluid Thermophysical Property Evaluation and the OpenSource Thermophysical Property Library CoolProp. Ind. Eng. Chem. Res. 2014, 53, 2498-2508. [CrossRef] [PubMed]

33. Sagerser, A.; Lieblein, S.; Krebs, R.P. Empirical Expressions for Estimating Length and Weight of Axial-Flow Components of VTOL PowerPlants; NASA: Cleveland, OH, USA, 1971.

34. Kakac, S.; Liu, H. Heat Exchangers Selection, Rating and Thermal Design, 2nd ed.; CPC Press: New York, NY, USA, 2002.

35. Shah, R.K.; Sekulic, D. Fundamentals of Heat Exchanger Design; John Wiley \& Sons, Inc.: Hoboken, NJ, USA, 2003. 
36. Onat, E.; Klees, W.G. A Method to Estimate Weight and Dimensions of Large and Small Gas Turbine Engines; NASA: Washington, DC, USA, 1979.

37. Fahlstrom, P.G.; Gleason, T.J. Introduction to UAV Systems, 4th ed.; Wiley \& Sons: Chichester, UK, 2012. 